\title{
RUSSIAN INDUSTRY IN OCTOBER 2016: CAUTIOUS OPTIMISM INSPIRED BY SALES ${ }^{1}$
}

There are hopes for industrial recovery from stagnation in Russia, according to analysis of the results of a survey that was carried out by the Gaidar Institute in October 2016. A positive shift in real sales dynamics coupled with slowly upgraded forecasts for the same is supplemented by a moderate, albeit positive, recovery of industrial production growth rates and a likely upward revision in assessments of finished product stocks. No visible positive shifts in output plans have been seen to date.

\section{Demand for industrial products}

The initial dynamics (balance of changes) of demand in 2016 exhibits stability that was unusual for the past few years. Following the traditional collapse early in the year, the indicator reached near-zero values and has been staying within a range of $-3 . .+2$ points for eight months since then, still reluctant to decline (as it always did at year end), the balance value in October stood at +2 points.

It was for the first time that the seasonally and calendar adjusted demand balance reached a positive value regardless of the fact that enterprises tend to undervalue sales dynamics. November and December might yet see a decline in demand that was typical of previous years, although enterprises forecast the opposite. Manufacturers' seasonally adjusted expectations were slowly, albeit consistently, infused with optimism in the second half of the year, thereby reaching the highest value (amid recession) in October. Russia's industrial sector is explicitly exhibiting a cautious optimism regarding prospects of the economic recession coming to an end.

Enterprises' sales volume assessments show that the industrial sector is highly satisfied (which is unusual amid recession) with the demand as it is now. Fifty six percent of the respondents said the situation was "normal" in October, which is in line with the average value recorded in the preceding quarter. This is the highest value in the recent economic recession, while the lowest one (45\%) was recorded in Q1 2016, that is, not at the peak of the recession. The lowest value stood at 23\% during the recession of 2008-2009, and it was recorded appropriately at the onset of the recession.

\section{Finished product stocks}

Enterprises' assessments of finished goods stocks in October were not as "normal" as they were in Q3 2016, which is rather due to respondents who didn't know the answer ("no answer"). However, the balance of responses describing the situation as "above normal" - "below normal" remained unchanged and negative. The latter indicates that the industrial sector is generally aware of being short of finished product stocks in terms of physical volume, however, the industry is yet not ready to increase them because it is not quite sure about consistency of the upward trends that apparently have

1 This paper was originally published in Monitoring of Russia's Economic Outlook No.19(37). 
been developing in recent months. This point is also supported by growth in the percentage of respondents who said they have "no answer" regarding stock assessment. The industrial sector has started looking for a new physical volume that could be optimal for finished product stocks, which may even concern the recovery stage, and there are enterprises that have not yet made up their mind about what it could be.

\section{Output}

Output dynamics in October exhibited positive changes after the collapse in September that was registered during our surveys. However, the changes will be as minor as they always were, that is, the industrial production growth rate will remain nearly zero, sending no signals of entering a recovery phase. No clear hopes for higher output in the coming months can be seen from enterprises' plans.

Seasonally adjusted balances in recent months are still positive, albeit extremely moderate in terms of magnitude. Moreover, production plans current balances are less optimistic than those of the same months of 2015. It appears that then industry's expectations were "cheered up" by very nearly official statements (promises) of an upcoming "rebound from the bottom of recession" that eventually did not happen. In early 2016, this was apparently the beginning of projecting the most pessimistic output plans ever in the course of the recession, even more pessimistic than those in Q1 2015, that is, at the onset of the recent recession.

\section{Industrial growth constraints}

Enterprises' moderately optimistic plans and forecasts coupled with the acknowledgment of being short of finished product stocks can be complemented with analysis of constraints to industrial growth, as enterprises see them.

Fifty percent of the enterprises still consider inadequate domestic demand as the principal constraint. For now, all the other factors are ranked much inferior to this constraint despite the fact that the majority of enterprises have managed to adapt to the volumes of their products that are in demand.

"Uncertainty about the condition and prospects of the Russian economy as it is now" is, as always, ranked second. This factor has been considered a constraint to a meaningful output strategy since the mid-2016, according to one third of Russian enterprises. However, $33 \%$ of the respondents mentioned "uncertainties", which is the lowest percentage ever in the course of the recent recession. This factor produced the strongest adverse effect on the Russian industrial sector in early 2016, when nearly a half of the respondents (enterprises) said it is a constraint, which resulted from, among other things, statements about reaching the bottom of recession and of an upcoming growth. The fact that government officials dropped giving promises of "rebounding from the bottom" and shifted to a more low-key rhetoric in 2016 did work in favour of the industrial sector, and enterprises have recently begun to seek ways towards recovery, having hunted down the specifics of the recent recession.

They also consider external demand, as they can hardly count on any growth in domestic demand. Therefore, $30 \%$ of the respondents (enterprises) pointed to low export demand, ranking it as the third most important fac- 
tor. A strengthening rouble might have become another reason for growing issues of external demand.

However, the dynamics of references to other constraints allows one to be doubtful about a strengthening rouble having a truly adverse effect on the Russian industrial sector in late 2016. Indeed, the constrain influence of such factor as "overdepreciated rouble exchange rate and appreciation of imported equipment and commodities" weakened by Q4 to its pre-recession level due to both a stronger rouble and two-year adaptation of the Russian industrial sector to a new exchange rate policy of the Bank of Russia. At the same time, an adverse effect on Russia's industrial output by such factor as "competition with imports" weakened to a 16-year low(!), that is, it became the most moderate since the impact of 14 -fold devaluation of the rouble in the aftermath of the Russian default of 1998.

Shortage of qualified personnel (that is still gaining momentum), especially regular labour force, was ranked first among the "resource constraints" to industrial growth in 2016. Twenty three percent of the respondents pointed to this factor. Nineteen percent of respondents who pointed to this factor was registered a year ago, the smallest percentage since the onset of the recession. Shortage of working capital has recently reached an all-time record in the entire period of monitoring (1993-2016) and is ranked second among the resource constraints. Shortage of machinery and equipment ("capacity shortage") and shortage of commodities and materials are ranked third and fourth respectively, 8-9\% of the respondents (enterprises) pointed to these factors. Finally, shortage of loans was mentioned by the smallest percentage $(3 \%)$ of the respondents. However, high loan rates were mentioned a bit more frequently (by 6\% of the respondents). The result obtained in Q4 2016 reflects the lowest percentage in the past 11 quarters of this year. 